Revista de
Economild
Contemporâned

\title{
EMISSÃO DE MOEDA, DE DÍVIDA PÚBLICA E CONVENÇÕES DURANTE A CRISE ECONÔMICA BRASILEIRA DE 20201
}

\begin{abstract}
Marco Flávio da Cunha Resende ${ }^{a}$

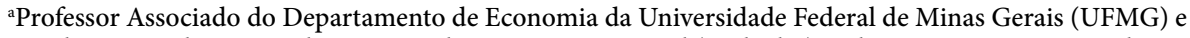
do Centro de Desenvolvimento e Planejamento Regional (Cedeplar), Belo Horizonte, MG, Brasil. Pesquisador do CNPq e do FINDE. ORCID: https://orcid.org/0000-0003-2069-2983.
\end{abstract}

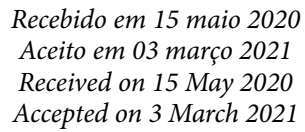

RESUMO: É comum o argumento de que a emissão de moeda é inflacionária e o descontrole da relação dívida pública/PIB leva à queda da confiança do mercado no futuro da economia. Além disso, defende-se frequentemente que ambas as situações comprometeriam o crescimento econômico. Neste artigo, objetiva-se demonstrar, com base na literatura pós-keynesiana, que a emissão de dívida pública e de moeda durante a atual crise da economia brasileira não levará à inflação e/ou à perda de confiança do mercado, tampouco afugentará o investimento privado, seja durante a recessão econômica de 2020, seja após sua superação. Pelo contrário, somente com essas medidas será possível resgatar a confiança do mercado e mitigar a queda da atividade econômica, o que facilitará a retomada do crescimento da economia brasileira.

PALAVRAS-CHAVE: moeda; dívida pública; inflação; investimento.

CLASSIFICAÇÃO JEL: E12; E60; H30.

Correspondência para: Marco Flávio da Cunha Resende

Contato: resende@cedeplar.ufmg.br

1 O autor agradece os comentários dos pareceristas da REC e do Grupo de Pesquisa em Financeirização e Desenvolvimento (Finde) a uma versão preliminar do artigo, eximindo-os dos erros porventura remanescentes. 


\title{
ISSUANCE OF CURRENCY, PUBLIC DEBT AND CONVENTIONS DURING THE 2020 BRAZILIAN ECONOMIC CRISIS
}

\begin{abstract}
The argument that currency issuance is inflationary and that the lack of control in the public debt/GDP ratio leads to a drop in market confidence in the future of the economy is a widespread one. According to this view, both situations also hinder economic growth. This article aims to demonstrate, based on the Post-Keynesian literature, that the issuance of public debt and currency during the current crisis in the Brazilian economy will not lead to inflation and/or loss of market confidence, nor will it drive away private investment, either during the economic recession in 2020 or after it. On the contrary, only with these measures it will be possible to restore confidence and mitigate the economic activity drop, fostering the recovery of the Brazilian economic growth.
\end{abstract}

KEYWORDS: currency; public debt; inflation; investment. 


\section{INTRODUÇÃO}

Em diversos países do mundo, inclusive no Brasil, a Covid-19 levou ao isolamento social e à queda abrupta da atividade econômica. Configurou-se um duplo choque, de oferta e de demanda, com enorme efeito recessivo. O Fundo Monetário Internacional (2020) projetou, para 2020, quedas de 4,4\% do produto mundial e, respectivamente, de 4,3\%, 8,3\% dos produtos dos Estados Unidos e da Área do Euro. Para o Brasil o organismo internacional projetou profunda recessão, com queda do produto (PIB) de $5,8 \%$ em 2020.

Essa será a maior recessão da história da economia brasileira, que já estava debilitada antes do advento da Covid-19. Nesse cenário, não é possível interromper o isolamento social e deixar o sistema de saúde colapsar, paralisando, em consequência, a própria economia. Faz-se necessário e é viável atacar simultaneamente as duas frentes de problemas: a saúde e a economia. O quadro atual é de queda abrupta e acentuada das receitas de empresas, governos e famílias, com endividamento, falências e desemprego crescentes. No Brasil, após severa recessão em 2015 e 2016 (com variação média anual do PIB de -3,4\%), observou-se um comportamento letárgico da economia entre 2017 e 2019, cujo crescimento médio foi de 1,2\%. Nesse cenário, boa parte de micro, pequenas e médias empresas está em situação financeira delicada. No campo das grandes empresas, alguns setores sofrem com os efeitos da pandemia mais que outros, como é o caso das companhias aéreas. A crise econômica que se instalou não tem precedentes. Com efeito, a recuperação da economia brasileira foi rápida após as maiores recessões da economia brasileira desde o pós-guerra, de 1981 a 1983 e de 1990. O mesmo ocorreu após a recessão de 2009, decorrente da crise financeira mundial de 2008. Porém, após a recessão de 2015 e 2016, a economia brasileira não se recuperou mais: a preços constantes, o PIB do quarto trimestre de 2019 encontrava-se 2,9\% abaixo do PIB do quarto trimestre de 2013 (IBGE, 2020).

O caminho mais seguro para combater a recessão e o desemprego é a emissão massiva de moeda e dívida pública para financiar políticas fiscal e creditícia expansionistas, baseadas em crédito subsidiado e em programas de transferência de renda para pessoas físicas, jurídicas e governos, detalhadas abaixo. Paralelamente, as políticas monetária e fiscal contracíclicas tradicionais devem ser aplicadas.

As medidas de injeção de capital e de liquidez no sistema financeiro, inclusive a permissão para o Banco Central (BC) comprar títulos de dívida pública e privada no mercado secundário (instituída pela PEC do “orçamento de guerra”), foram importantes para sustentar os preços neste mercado, evitar insolvências de instituições financeiras e controlar o risco sistêmico, mas não estimularam o crédito para empresas e consumidores. Ou seja, o dinheiro desta assistência de liquidez do BC 
não chegou até a economia real. Bancos preferiram manter-se líquidos a arriscar elevar o crédito em cenário tão adverso. Faltou a necessária permissão para que o $\mathrm{BC}$ comprasse títulos do Tesouro em mercado primário, financiando os gastos da União com emissão de moeda. ${ }^{1}$

Do mesmo modo, era pequena a chance de deslanchar o crédito para pagamento por até dois meses da folha salarial de micro e pequenas empresas (MPE) em até dois salários-mínimos. Nesse programa, o Tesouro Nacional garante $85 \%$ dos recursos e os bancos garantem os 15\% restantes, condicionado à proibição de demissão dos funcionários nos dois meses subsequentes à contratação do crédito. Trata-se de crédito com taxa de juros de $3,75 \%$ ao ano, com prazo de 36 meses para sua quitação e período de carência de seis meses. Uma parcela das MPE não podia se arriscar contraindo uma dívida para manter seus empregados e começar a saldar a dívida já em seis meses, num cenário de absoluta incerteza sobre o porvir. Mesmo quando não decretaram falência, uma parcela de seus funcionários foi demitida, o que resultou em uma subutilização do crédito disponível para pagamento da folha salarial. ${ }^{2}$ Ademais, os bancos não se arriscaram na alocação de recursos para tal finalidade, já que 15\% do valor dos empréstimos não tinha a garantia do Tesouro Nacional. Por outro lado, o governo iniciou o pagamento do denominado Auxílio Emergencial de R\$600,00 a trabalhadores informais e pessoas carentes, enquanto o rendimento médio do trabalhador no setor informal é de cerca de $\mathrm{R} \$ 1.400,00$ mensais, o que representou substancial queda da demanda de consumo dessa parcela da população. Outras medidas adotadas contribuíram para minorar o problema, mas sem solucioná-lo. Cita-se o Programa Emergencial de Manutenção do Emprego e da Renda (BEM), com redução proporcional da jornada de trabalho e de salário, ou suspensão do contrato de trabalho; e o Programa Nacional de Apoio às Microempresas e Empresas de Pequeno Porte (Pronampe).

O único caminho seguro para combater a recessão e o desemprego instalados é a emissão massiva de moeda e de dívida pública, a fim de transferir urgentemente recursos monetários em montantes bem superiores aos atuais para desempregados dos setores formal e informal, empresas e governos municipais e estaduais, paralelamente às políticas monetária e fiscal contracíclicas tradicionais, o que mitigaria a queda da

$1 \mathrm{O} \$ 1^{\circ}$ do artigo 164 da Constituição Federal veda ao BC conceder, direta ou indiretamente, empréstimos ao Tesouro Nacional e a qualquer órgão ou entidade que não seja instituição financeira. Porém, essa é uma restrição autoimposta pela legislação brasileira. Sobre essa e outras restrições autoimpostas que dificultam a coordenação entre as políticas fiscal e monetária, ver Modenesi e Pimentel (2020).

2 Conforme Moreira (2020), dos R 20 bilhões disponibilizados para o primeiro mês do programa, menos de R\$ 7 bilhões foram contratados, passadas três semanas do início da oferta. 
demanda e da oferta agregada. Seriam bem-vindos: um programa de transferência de renda para ampla parcela da população, cerca de 100 milhões de pessoas, com valores mensais de um salário-mínimo, com duração até o final de 2020 e possibilidade de prorrogação; um programa de crédito para MPE e médias empresas $100 \%$ garantido pelo Tesouro, com taxa de juros zero somada à taxa de intermediação bancária, carência de dois anos, garantia da manutenção dos empregos e vinculado ao pagamento da folha salarial; um programa de isenção temporária para empresas de impostos municipais, estaduais e federais; e transferência de recursos para estados e municípios, cuja queda de arrecadação ameaça sua capacidade de arcar com a folha salarial do funcionalismo público enquanto aumentam os gastos com saúde - os critérios de transferência de recursos para estados e municípios devem contemplar as isenções de impostos, as disparidades regionais do país e os graus variados de necessidade de gastos com saúde das regiões. Essas medidas não estariam sujeitas à preferência pela liquidez de bancos, nem de empresas e famílias, que gastariam com sua sobrevivência os recursos recebidos. Todavia, o governo federal tem sido lento na formatação e implementação das medidas de combate à crise da economia e da saúde, e aquelas implementadas parecem ser insuficientes. A equipe econômica, preocupada com o lado fiscal, parece não ter entendido a natureza da crise que se instalou.

Autores ortodoxos argumentam que a emissão de moeda é inflacionária e que o descontrole da relação dívida/PIB do governo leva à queda da confiança do mercado no futuro da economia. Ambas as situações afugentariam o investimento produtivo e, consequentemente, comprometeriam o crescimento econômico. Postulam, também, que mesmo que a emissão de moeda e de dívida pública possam amenizar a recessão no curto prazo, após superadas as crises da saúde e da economia haveria recrudescimento da inflação e perda de confiança do mercado e, em consequência, o investimento privado desabaria.

O objetivo deste artigo é demonstrar que a emissão de dívida pública e de moeda (monetização da dívida da União) não levará à inflação, ao pânico e/ou perda de confiança do mercado, nem afugentará o investimento privado, quer durante a crise econômica de 2020, quer após sua superação - o investimento já colapsou e há pressões inflacionárias, mas por outros motivos. Pelo contrário, somente com essas medidas será possível resgatar a confiança e mitigar a queda da atividade econômica, além de facilitar a retomada do crescimento econômico.

Além da introdução, o artigo contém quatro seções. Na próxima seção são analisados os dois canais da pressão inflacionária decorrente da emissão de moeda, quais sejam, o canal da demanda e o das expectativas, segundo as óticas da teoria ortodoxa e póskeynesiana, como também são analisadas a validade da emissão monetária e a necessidade do aumento das operações compromissadas do BC no âmbito do Regime de Metas de 
Inflação. ${ }^{3} \mathrm{Na}$ seção dois é avaliada, no contexto da pandemia em curso, a relação entre a dívida pública/PIB e a confiança do mercado na sua estabilidade. Na seção seguinte analisa-se os possíveis efeitos da emissão de moeda e de dívida pública sobre a inflação e o crescimento da economia brasileira no período pós-recessão econômica. Na seção quatro constam as conclusões do artigo.

\section{EMISSÃO DE MOEDA E INFLAÇÃO}

\subsection{TEORIA QUANTITATIVA DA MOEDA E O CANAL DA DEMANDA}

Conforme a teoria convencional, há dois canais por meio dos quais a emissão de moeda pressiona a inflação: o canal da demanda e o das expectativas. No primeiro caso, a explicação baseia-se na Teoria Quantitativa da Moeda (TQM), em que M.V = P.Y (M = quantidade de moeda, $\mathrm{V}$ = velocidade de circulação da moeda, $\mathrm{P}=$ nível de preços, e $\mathrm{Y}=$ quantidade de bens e serviços produzidos). A TQM supõe V estável e Y constante no curto prazo, e que a relação de causalidade se dá de $M$ para $P$. Mas essas são apenas hipóteses.

Adeptos da teoria ortodoxa acreditam que $\mathrm{V}$ é estável porque assumem a hipótese de que o mercado contém todas as informações necessárias para o cálculo matemático ou estatístico requerido para se prever a trajetória futura de variáveis econômicas. Essa hipótese subentende uma outra: a de que os dados são estacionários, prevalecendo na economia um processo ergódico (DOW, 1986) que, por sua vez, permite ao agente acessar o futuro por meio do cálculo estatístico (probabilístico) realizado a partir dos dados do presente e do passado. ${ }^{4}$

Essa hipótese não é consensual na literatura. A Escola Pós-Keynesiana entende que os sinais do mercado, dados, por exemplo, pelas variações dos preços, informam sobre o presente, mas não sobre o futuro. Se a demanda de batata está maior que sua oferta, seu preço sobe no presente, ensejando maior lucro ao produtor de batatas, mas não informa quais serão os preços da batata e seus custos de produção ao longo dos próximos dez ou quinze anos, para que o agente possa se endividar e investir comprando uma fazenda de batatas com a perspectiva de lucro. Na literatura pós-keynesiana, ao contrário da visão da literatura ortodoxa, prevalece a incerteza fundamental, isto é, não probabilística, pois o mercado não

3 Assumimos o critério de Mollo (2004) para classificar as escolas do pensamento econômico: são ortodoxas as escolas que aceitam a neutralidade da moeda pelo menos no longo prazo e heterodoxas as que não a aceitam nem no curto nem no longo prazo.

4 Na literatura ortodoxa, o cálculo probabilístico se refere à incerteza do agente. Na literatura pós-keynesiana, ele se refere a risco, enquanto a incerteza ocorre quando o cálculo atuarial não é possível. 
fornece de modo completo as informações requeridas para o cálculo probabilístico sobre o porvir. ${ }^{5}$ Neste caso, o agente econômico não poderia maximizar sua função objetivo fazendo uso de esperança matemática conforme verifica-se na literatura ortodoxa, pois a esperança matemática é construída com dados do passado e, como os eventos não seriam estacionários, o passado não é um bom guia estatístico do futuro. Assim sendo, a economia é permeada pela "incerteza fundamental" e pela preferência pela liquidez, o que torna a moeda não neutra mesmo no longo prazo. ${ }^{6}$ Conforme Resende (2019),

No novo paradigma da ciência econômica inaugurado por Keynes, a incerteza fundamental está presente e, por isso, a trajetória futura das variáveis econômicas não pode ser conhecida a priori nem mesmo em termos probabilísticos. A incerteza existe porque há decisões cruciais, que destroem as condições iniciais a partir das quais elas ocorrem, como é o caso das decisões de investimento. Consequentemente, eventos econômicos não são replicados e, então, as condições para o cálculo probabilístico não existem. Isto impede os agentes assumirem "expectativas racionais" e um comportamento maximizador, inviabilizando mecanismos automáticos de mercado que corrijam desvios da economia em relação a um equilíbrio ótimo de longo prazo. Neste sentido, a preferência pela liquidez e o comportamento convencional resultam da tentativa dos agentes de obter proteção (contra perdas de riqueza) diante da incerteza, condicionando a trajetória futura da economia e impedindo a neutralidade da moeda. Como a informação sobre o futuro é sempre incompleta, as trajetórias futuras das variáveis econômicas serão o resultado do conjunto de decisões de gastos e alocação de riqueza dos agentes no presente. (RESENDE, 2019, p. 121)

Logo, na presença de incerteza fundamental não há garantia de retorno dos investimentos. Por isso, empresários são ariscos na sua função de investir e gerar emprego, como também os bancos, ao concederem crédito. Sinais de crise ou desaceleração econômica podem levar os agentes a preferirem a liquidez da moeda em detrimento

\footnotetext{
5 Não se trata de informações que existem em potencial, mas que não são adequadamente acessadas por um problema de informação imperfeita ou assimetria de informações e falhas de mercado. A incerteza fundamental, ou em sentido forte, existe quando o agente não consegue construir, mesmo acessando todas as informações que o mercado oferece, uma distribuição de probabilidade única, aditiva e confiável, porque não obtém uma lista completa dos eventos futuros possíveis (DEQUECH, 1999a). Para pós-keynesianos, o agente econômico é um ser racional, porém, sua razão é construída à luz da incerteza fundamental. Segundo Carvalho (2015, p. 47), "Keynesian agents make their choices as rationally as neoclassical agents. The difference is that, under uncertainty, agents choose among a subjectively-created list of outcomes while orthodox analysis postulates choice among objectively-determined lists of outcomes".

6 Ver detalhes em Mollo (2004) e Carvalho (2015).
} 
da alocação da riqueza em investimentos produtivos, pois, apesar de gerarem renda e emprego, são ilíquidos, e sem liquidez a preservação da riqueza não está garantida (CARVALHO, 2015; DOW, 1986). O resultado pode ser a deficiência de demanda, que leva a desemprego, queda dos salários reais e concentração da renda. ${ }^{7}$ Além disso, $\mathrm{V}$ deixa de ser estável. Se a preferência pela liquidez aumenta, a moeda circula menos e V cai. Portanto, pode haver aumento de $\mathrm{M}$ compensado pela queda de $\mathrm{V}$, o que torna a emissão de moda sem efeito sobre a inflação. ${ }^{8}$

Por fim, analisando a identidade contábil da qual parte a TQM, mesmo que V não caia, Y não será constante se não houver pleno emprego. ${ }^{9}$ Logo, quando o aumento de $\mathrm{M}$ se transforma em aumento da demanda porque $\mathrm{V}$ não caiu, o excesso de demanda fomentará o aumento da produção e do emprego (aumento de Y) quando há muita capacidade ociosa, como é o caso atual da economia brasileira, ao invés de estimular a inflação. De 2008 até a elaboração deste artigo, Estados Unidos, Zona do Euro, Japão e China emitiram juntos mais de US\$ 15 trilhões e não houve inflação descontrolada nessas regiões ou no mundo - com a crise financeira mundial de 2008, a incerteza aumentou e $\mathrm{V}$ caiu, compensando aumentos em $\mathrm{M}$. A melhora no crescimento de algumas dessas economias em 2018 e 2019 mostrou que o recente aumento em V se traduziu em aumento de demanda que, não obstante, rebateu em aumento da produção (oferta), sem gerar inflação.

Tampouco a emissão de moeda causará inflação pelo canal das expectativas, que estão ancoradas na recessão contratada. Porém, em contexto de crescimento econômico, a emissão de moeda pode resultar em inflação. ${ }^{10}$ Quando a economia está crescendo, a incerteza diminui, deprimindo a preferência pela liquidez. Nesse contexto, aumentos de $M$ não são compensados por quedas em $\mathrm{V}$, enquanto a capacidade ociosa da economia diminui e ela aproxima-se do pleno emprego, situação em que $Y$ tende a ser constante. Logo, aumentos em $\mathrm{M}$ podem reverberar em aumentos em $\mathrm{P}$ - supondo que a relação

7 Explica-se, assim, os dois grandes problemas da economia, segundo Keynes (1988): desemprego involuntário e concentração da renda.

8 Há farta evidência empírica contra a hipótese monetarista de estabilidade de V. Veja, por exemplo, Anderson, Bordo e Duca (2015) e Gentle e Jones (2015). Segundo esses autores, após a crise do subprime, $\mathrm{V}$ decresceu nos Estados Unidos da América. A política monetária não convencional implementada na última década em vários países contesta a concepção monetarista da inflação. Os bancos centrais das principais economias promoveram enorme expansão de suas bases monetárias sem impacto inflacionário. A visão monetarista da inflação é um dogma que contraria frontalmente a experiência dos últimos anos.

9 O mesmo argumento pode ser usado quando se considera a taxa de desemprego não aceleradora de inflação (NAIRU).

${ }^{10}$ Keynes (1988) apresenta quatro motivos para que a inflação aumente com o crescimento econômico antes que o pleno emprego seja alcançado, sendo que quanto mais próximo o produto estiver do seu nível de pleno emprego, maiores serão as pressões inflacionárias. 
de causalidade se dá de M para P. Contudo, o canal das expectativas talvez seja ainda mais potente para explicar a inflação.

\subsection{CANAL DAS EXPECTATIVAS}

Se na economia em que vivemos prevalece a incerteza fundamental, as expectativas não se baseiam em "esperança matemática" ou no cálculo atuarial, mas são formadas a partir de convenções. Estas são crenças compartilhadas que, quando são otimistas, revelam-se um redutor de incertezas, ancoram as expectativas e conferem confiança para o empresário realizar investimentos (CARVALHO, 2014). ${ }^{11}$ Se a crença compartilhada tiver cunho pessimista, os agentes alocam sua riqueza em ativos líquidos no mercado financeiro e o investimento e o emprego se retraem. Portanto, as expectativas assumem papel central na determinação do ciclo econômico e só o governo e suas políticas podem emitir os sinais que o mercado não é capaz de emitir para estimular e manter acesa a convenção otimista sobre o futuro, bem como coordenar as decisões de investimento (CARVALHO, 1992b; RESENDE; TERRA, 2017).

Portanto, se o investimento privado é sensível às convenções e expectativas, a moeda tem um papel central. A demanda por liquidez (moeda) se dá em detrimento da demanda por máquinas, equipamentos etc. (investimento). Por isso, quanto maior for a incerteza, menores serão o investimento e o crescimento econômico, isto é, maior será a fuga para a liquidez.

De outro lado, uma teia de contratos é estabelecida para reduzir a incerteza e permitir ao empresário arriscar ao fazer investimentos. Há na economia contratos de toda natureza, inter e intrafirmas e setores, entre pessoas jurídicas e físicas, etc. Contudo, contratos requerem uma unidade de conta cujo valor seja estável. Tomemos o contrato salarial como exemplo. Quem aceitaria receber em troca do seu trabalho ao longo de um ano inteiro um ativo que perde valor? Para ser unidade de conta de contratos, o ativo deve ter valor estável. No caso da moeda, sua oferta é escassa em relação à sua demanda, contribuindo para a estabilidade do seu valor. Conforme a literatura pós-

11 "Uma convenção, portanto, é um redutor de incertezas ao tornar previsível o comportamento daqueles que se assume compartilhar a mesma crença" (CARVALHO, 2014, p. 248). "Na literatura Pós-Keynesiana, as convenções são crenças compartilhadas, associadas a uma regra coletiva de comportamento, não-determinísticas, de caráter mimético e baseadas na intersubjetividade entre os agentes. As convenções não eliminam a incerteza, mas podem ancorar por algum tempo as expectativas, pois ensejam confiança nestas, conferindo estabilidade momentânea ao sistema econômico, porém são, ao mesmo tempo, voláteis, pois nada mais são do que mera crença compartilhada" (RESENDE, 2019, p. 121, grifo no original). Sobre o conceito de convenção em Keynes e pós-keynesianos, ver Keynes (1988, cap. 12), Carvalho (2014; 2015), Dequech (1999b), Modenesi et al. (2013) e Modenei e Modenesi (2015). 
keynesiana, "a disponibilidade de moeda deve ser relativamente insensível à demanda" (CARVALHO, 1992a, p. 180) por causa das suas negligenciáveis elasticidades de produção e substituição. Deste modo, a moeda torna-se unidade de conta de contratos dada a negligenciável sensibilidade da sua oferta em relação à sua demanda; com isso, os contratos conferem ao valor da moeda uma estabilidade ainda maior e ela se torna, também, reserva de valor. Portanto, é da sua relação com contratos que a moeda deriva seu atributo de ativo de liquidez máxima da economia (CARVALHO, 1992a), exercendo três funções: unidade de conta, reserva de valor e meio de pagamento.

Contudo, ser a moeda unidade de conta de contratos não é garantia de inflação sob controle, pois nem todas as transações são amparadas por contratos e estes têm um prazo de vigência. A inflação desorganiza a atividade produtiva porque eleva a incerteza ao provocar uma redução dos prazos de vigência dos contratos, entre outros motivos. Foi o que ocorreu no Brasil na década de 1980 e início dos anos 1990. Os contratos, inclusive os salariais, eram reajustados a cada três meses, de modo que era impossível prever quais seriam os novos preços e salários após cada trimestre. A moeda perdia, então, sua capacidade de coordenar a atividade econômica por meio de contratos. O resultado foi o colapso dos investimentos durante o período que ficou conhecido como a "década perdida".

Portanto, embora ser padrão de conta para contratos contribua para a estabilidade do valor da moeda, faz-se ainda necessária a convenção social de que a moeda tem valor estável para que os preços fiquem comportados (TERRA, 2019). Deve haver uma crença compartilhada na sociedade de que a perda de valor da moeda (inflação), se houver, será pequena. A estabilidade do valor da moeda está ligada a uma convenção social (crença compartilhada) que é alimentada pela negligenciável sensibilidade da sua oferta em relação à sua demanda. Quando a emissão de moeda é tal que o axioma de sua negligenciável elasticidade de produção é desrespeitado, pode surgir a convenção de que haverá perda do seu valor (inflação). ${ }^{12}$ Neste caso, os agentes buscarão proteger sua

12 Não necessariamente a emissão monetária introduz uma convenção de que a inflação subirá. Pelo canal da demanda, se V cai e/ou Y está longe do seu nível de pleno emprego, a emissão monetária não pressiona a inflação e, por isso, ela pode estabelecer pelo canal das expectativas uma convenção pró-crescimento ao invés de pró-inflação. Seja pelo canal da demanda seja pelo canal das expectativas, não há relações de causalidade pré-determinadas e mecânicas entre M, V, P e Y, devido à presença da incerteza fundamental. Mesmo com a brutal expansão monetária nos Estados Unidos após 2008, a proporcional queda de V implicou uma oferta de moeda com relativa indisponibilidade frente a sua demanda. Todavia, a emissão de moeda pode ser perigosa em contexto de aceleração do crescimento econômico que, por si só, já engendra pressões inflacionárias. O impacto sobre preços dependerá das circunstâncias ligadas à oscilação da preferência pela liquidez, ao grau de capacidade ociosa, a mudança de convenções etc. Para Keynes (1988, p. 200), "os preços [...] sobem progressivamente à medida que o emprego aumenta", devido a quatro motivos apresentados no capítulo 21 da sua Teoria Geral. Se a esse aumento de preços agregam-se expectativas de inflação, o efeito da emissão de moeda será indesejado - a ideia de que, para Keynes, a oferta agregada é um L invertido é uma lenda enganosa. 
riqueza, levando à corrida para compra de bens e serviços e outros ativos como imóveis e dólar, o que resultará em inflação, isto é, as expectativas de inflação acabam se autorrealizando. Ademais, uma vez solidificada a convenção de uma inflação elevada, produtores e comerciantes se antecipam no processo de reajuste de preços visando evitar perdas, o que acelera a inflação. É por isso que, em condições normais, em que não há uma recessão instalada, a emissão descontrolada de moeda, isto é, aquela que desrespeita o axioma de negligenciável elasticidade de sua produção, pode gerar inflação ao invés de crescimento econômico. Esta talvez seja a principal crítica à Modern Monetary Theory, que defende a ausência de restrição para o governo financiar seus gastos na própria moeda, de modo que a possa emitir até que a economia alcance o pleno emprego (TYMOIGNE; WRAY, 2013; WRAY, 1998).

Porém, o quadro atual da economia brasileira é de elevada capacidade ociosa e forte recessão, e esta irá ancorar os preços, seja por meio do canal das expectativas (convenção de inflação baixa) seja porque V cairá e Y ficará longe do pleno emprego. Logo, a emissão de moeda para financiar as medidas emergenciais de combate à crise econômica não provocará inflação. A única possibilidade de aceleração da inflação durante a crise decorreria de um grande aumento do preço do dólar, devido a uma corrida para o dólar (fuga para a liquidez). Mas esse problema será solucionado se o BC adotar controle de saída de capitais.

Por fim, há o argumento de que a emissão de moeda levará ao aumento da dívida pública por meio da elevação das operações compromissadas do BC, requeridas, por sua vez, a fim de fazer a taxa de juros do interbancário convergir para a meta Selic, estipulada no âmbito do regime de metas de inflação. Logo, a emissão de moeda não seria mais vantajosa em relação à emissão de dívida pública para financiar os gastos públicos emergenciais de sustentação do emprego e do PIB. Vejamos este tópico a seguir.

\subsection{EMISSÃO DE MOEDA E O REGIME DE METAS DE INFLAÇÃO}

Após a crise cambial brasileira de janeiro de 1999, adotou-se no país um regime de política macroeconômica baseado no tripé: metas de inflação, taxa de câmbio flexível e metas fiscais. Para tanto, foi estabelecido o regime de metas de inflação (RMI), em que a inflação é controlada pelo ajuste na taxa de juros básica da economia, que deve convergir para a meta Selic estabelecida pelo Comitê de Política Monetária do BC, cujo único mandato é a estabilidade de preços.

No Brasil, é vedada pela Constituição Federal a compra pelo BC de emissões primárias de títulos do Tesouro Nacional. Porém, uma Proposta de Emenda Constitucional poderia retirar essa vedação, senão de modo permanente, ao menos para períodos de calamidade pública. Neste caso, os gastos emergenciais de combate à recessão durante a pandemia 
poderiam ser financiados pela emissão monetária. O Tesouro venderia títulos públicos diretamente para o BC, que creditaria na Cona Única que o Tesouro mantém no BC o valor referente a compra dos títulos. Para financiar os gastos emergenciais do governo, o BC, então, debitaria o valor dos gastos na Conta Única e creditaria na sua conta de reservas bancárias que, juntamente com o papel moeda em circulação, constitui a base monetária e faz parte do passivo do $\mathrm{BC}$, ampliando a base monetária. ${ }^{13}$

Todavia, uma vez que o BC tem a função de fazer a taxa de juros no interbancário convergir com a meta Selic, sua política monetária deve prover o sistema bancário de liquidez compatível com a meta de juros estipulada. A ampliação das reservas bancárias, decorrente da compra pelo BC de emissões primárias de títulos do Tesouro Nacional (emissão de moeda), ceteris paribus, aumentaria a liquidez do sistema fazendo a taxa de juros cair abaixo da meta Selic, desrespeitando o RMI. Para que a taxa de juros não caia, Pessoa (2020), Zilberman e Silva (2020) e Goldfajn (2020) argumentam que o BC teria que esterilizar o aumento da base monetária por meio da venda de compromissadas, implicando aumento da dívida pública. Logo, seria melhor emitir diretamente a dívida pública para financiar os gastos emergenciais, visto que a emissão de moeda poderia comprometer a credibilidade do RMI, conquistada a duras penas. Conforme Goldfajn (2020):

A emissão monetária significa elevar o passivo reservas bancárias/depósito voluntário (ou compromissadas no Brasil) [...]. [O] aumento do passivo do BC eleva a dívida do governo. Tanto as reservas [bancárias] remuneradas quanto as compromissadas são passivos remunerados pela taxa de juros básica do governo (Selic no Brasil), custo equivalente a emissão de títulos do Tesouro Nacional (TN) de duração de um dia (as chamadas Letras Financeiras Tesouro). Endividar-se via TN ou via "emissão monetária" (aumento do passivo do BC) tem o mesmo custo para a sociedade. $\mathrm{Na}$ ausência de repressão financeira (e/ou controle total de capitais), a sociedade tem a opção de reter ou não esses passivos do BC, remetendo ao exterior ou comprando bens ou ativos reais. Há sempre a possibilidade de fuga da moeda... Minha avaliação é que tanto a nossa situação fiscal quanto o quadro institucional pioraram. Portanto, o risco Brasil e os juros de equilíbrio devem ter se elevado na crise, não caído. O risco percebido dos detentores da dívida $(\mathrm{BC}+\mathrm{TN})$ deve ter subido nesta crise [...] Forçar/pressionar uma remuneração muito abaixo do equilíbrio pode ter consequências que variam de toleráveis a dramáticas. O tolerável seria uma depreciação significativa do real (overshooting), mas controlada

13 O passivo do BC é composto pela base monetária, pela Conta Única do Tesouro Nacional e pelo patrimônio Líquido do BC. 
[...] Já a depreciação descontrolada ocorre quando processos de overshooting desencadeiam dinâmicas perversas, [...] que afete [a] inflação a curto e médio prazo, [com] necessidade de subida de juros na crise. O mais dramático seria perdermos a âncora monetária. Nesse caso, o experimento malsucedido na crise pode levar a uma fuga da poupança nacional, perda de anos de credibilidade na moeda. [...] Mas não podemos tomar essa credibilidade da moeda como dada. Essa conquista tem que ser cultivada e trabalhada permanentemente. Portanto, falar em emitir moeda como uma solução sem custos me parece um voluntarismo perigoso e desnecessário. (GOLDFAJN, 2020, n.p.)

Ao afirmar que "A emissão monetária significa elevar o passivo reservas bancárias/ depósito voluntário (ou compromissadas no Brasil)", Goldfajn (2020, n.p.) está assumindo, implicitamente, que o aumento da base monetária decorrente da emissão de moeda será necessariamente enxugado, por meio da emissão de compromissadas, que implica aumento da dívida pública. Provavelmente, o autor entende ser necessário emitir compromissadas para que a taxa de juros convirja para a meta Selic, e esta convergência é requerida para que a taxa de inflação, por sua vez, convirja para a meta estabelecida, conferindo credibilidade ao RMI e à moeda brasileira. ${ }^{14}$ Pessoa (2020), Zilberman e Silva (2020), Barbosa (2020), Oreiro (2020) e Marconi (2020) defendem esse argumento de modo explícito.

Porém, Oreiro (2020) e Marconi (2020) argumentam que a emissão de compromissadas não será necessária porque a brutal recessão econômica levará a inflação para níveis bem abaixo da meta. No contexto atual de elevada e crescente capacidade ociosa, aumentos de demanda estimularão a oferta, sem causar inflação. Com efeito, o IPCA de abril de 2020 registrou uma deflação de 0,31\%. Isto quer dizer que a hipótese de Pessoa (2020), Zilberman e Silva (2020) e Goldfajn (2020), assumida explicitamente pelos dois primeiros, é equivocada, pois não haverá a necessidade de enxugamento da base monetária para fazer a inflação convergir para a meta. Se o aumento da base monetária implica a queda dos juros no interbancário, então a meta Selic deve cair mais rapidamente, acompanhando o aumento da base monetária proporcionado pelo financiamento dos gastos emergenciais do governo por meio da emissão de moeda. Para tanto, o Comitê de Política Monetária (Copom) do BC deveria ter intervalos de reuniões inferiores a 45 dias durante esse período. Reuniões extraordinárias do Copom poderiam ocorrer a cada 15 dias, enquanto fosse necessário, fazendo a meta Selic acompanhar a expansão da base monetária e a queda da taxa de juros. Haveria uma

${ }^{14}$ Goldfajn (2020) foi publicado em 5 de maio de 2020, quando a Selic estava em 3,75\% ao ano. 
inversão: a meta Selic é que acompanharia a queda dos juros do interbancário. Isso não comprometeria a credibilidade do RMI e da moeda brasileira se a inflação é cadente, e não há por que supor que ela será ascendente: exceto na presença de intensa depreciação cambial, haverá apenas aumentos localizados e pontuais de preços, pois a recessão instalada será a maior da história da economia brasileira até aqui, além de haver, também, recessão e queda da inflação no mundo. Ademais, o Copom acompanharia a situação a cada 15 dias e poderia parar o processo de emissão monetária se os sinais dados pelo movimento dos preços fossem outros. Trata-se de situação extraordinária e emergencial. ${ }^{15}$

Além disso, Pessoa (2020), Goldfajn (2020), Zilberman e Silva (2020), Barbosa (2020) e Marconi (2020) não consideram mudanças na preferência pela liquidez dos agentes e outros fatores que condicionam a base monetária. Se a emissão de moeda ocorrer simultaneamente à expansão da demanda líquida por divisas externas, por exemplo, o volume de operações compromissadas será menor, ceteris paribus. Do mesmo modo, o aumento da incerteza e da preferência pela liquidez pode implicar o aumento de papel moeda em poder do público (PMPP), levando a uma menor ampliação dos depósitos à vista e das reservas bancárias e, consequentemente, a um menor volume de operações compromissadas necessário para fazer convergir a taxa de juros para a meta Selic. De outro lado, bancos podem aumentar as reservas bancárias (preferência pela liquidez), estimulando o aumento das compromissadas. Portanto, a afirmação de Barbosa (2020, n.p.) de que há "esterilização monetária de $100 \%$ das ações do TN [Tesouro Nacional] pelo BC" é equivocada, como também se equivocam, nesse mesmo sentido, Pessoa (2020), Goldfajn (2020), Zilberman e Silva (2020) e Marconi (2020). Com efeito, Reuters (2020) aponta indícios de que o pagamento de R\$600,00 a pessoas carentes no âmbito das medidas emergenciais levou ao aumento do PMPP, pois o dinheiro não fluiu com rapidez para depósitos à vista na rede bancária.

Não obstante, Goldfajn (2020) chama a atenção para dois riscos decorrentes da emissão monetária. Segundo o autor, "na ausência de repressão financeira (e/ou controle

15 Paula e Ferreira (2020) propõem uma solução para eliminar as operações compromissadas, por meio de uma mudança na institucionalidade da política monetária brasileira: a adoção do sistema de "depósitos voluntários remunerados”. Neles, "o BCB paga um piso de remuneração sobre as reservas bancárias excedentes com o objetivo de administrar a liquidez no mercado interbancário e manter a meta de juros definida pelo Conselho de Política Monetária (Copom), como ocorre no Federal Reserve (FED), algo que ficou para um projeto de lei complementar. Atualmente, o Banco Central do Brasil utiliza apenas depósitos compulsórios, taxa de redesconto e operações compromissadas como instrumentos de política monetária. Com depósitos remunerados, o Banco Central pode expandir seu balanço, mas sem precisar retirar liquidez do sistema bancário. Essa medida alternativa, portanto, permitiria ao Banco Central reduzir os níveis de compulsórios a zero (um custo implícito no spread de juros), e ainda, diminuir gradativamente o uso de operações compromissadas, que correspondem perto de $1 / 3$ da dívida pública bruta, em geral, com vencimentos no curtíssimo prazo" (PAULA; FERREIRA, 2020). 
total de capitais), a sociedade tem a opção de reter ou não esses passivos do BC, remetendo ao exterior ou comprando bens ou ativos reais". Mas qual seria o risco de haver aumento da compra de bens ou ativos reais? O único risco que o país corre atualmente é ver estimulada a expansão do seu produto e do emprego, pois o risco de pressão inflacionária não existe diante do severo quadro recessivo no qual a economia mergulhou. De outro lado, há o risco de fuga de capitais, que elevaria ainda mais a taxa de câmbio, a ponto de gerar um quadro de estagflação. Contudo, o BC poderia fazer reuniões quinzenais do Copom e sucessivamente calibrar a redução da Selic paralelamente à monetização da dívida pública e, ao acompanhar de perto todo o processo, caso seja necessário, adotar controle de saída de capitais. ${ }^{16}$ Outra opção seria o BC atuar no mercado secundário de título público federal, o que é permitido pela PEC no 10/2020, para afetar o segmento mais longo da curva de juros. Desse modo, o BC garantiria uma remuneração positiva aos detentores de títulos de prazo mais longo, enquanto a Selic pode se reduzir até alcançar zero, se for o caso, evitando, dessa maneira, uma possível fuga de capitais. ${ }^{17}$ As economias do Peru e do Chile são também economias emergentes, como a brasileira, e levaram suas taxas básicas de juros para $0,25 \%$ e $0,50 \%$ ao ano, respectivamente, segundo Rittner (2020), projetando taxas de juros reais negativas para 2020 e sem provocar uma fuga de capitais que implicasse pesadas desvalorizações de suas moedas.

Portanto, são dois os argumentos contrários à emissão monetária para financiar políticas emergenciais de combate à crise: i) gerar inflação; e ii) ser nulo o efeito da substituição do aumento da dívida pública por esse mecanismo de financiamento, visto que a emissão de moeda levaria à ampliação das operações compromissadas, elevando a dívida pública. Este último ponto implica a hipótese de que a Selic não pode cair, o que não faz sentido tendo em vista a magnitude da recessão esperada e que, já em abril de 2020, houve deflação do IPCA de 0,31\%. Ademais, conforme Oreiro (2020), mesmo que o BC não queira reduzir a meta Selic, a monetização do déficit do governo e posterior aumento das operações compromissadas é mais vantajosa do que a emissão direta de dívida do Tesouro. Isso ocorre porque as taxas de juros incidentes nas compromissadas são mais baixas que as taxas pagas sobre os títulos da dívida pública, cujo prazo de maturidade é maior, o que reduz o custo médio de rolagem da dívida pública e favorece a opção pela monetização da dívida durante a recessão econômica -

16 Durante a Crise da Ásia de 1997, a Malásia adotou controles de capitais com sucesso. Para esse e outros exemplos de adoção exitosa de controles de capitais, ver Carvalho e Sicsú (2007) e Paula, Oreiro e Silva (2003).

17 A PEC no 10/2020 (PEC do Orçamento de Guerra) confere a possibilidade de manejo da curva de juros pelo BC. A operação sugerida teria custos para o Tesouro, na medida em que corresponderia ao inverso da operação twist, em que a autoridade monetária compra títulos públicos de longo prazo, reduzindo o segmento mais longo da curva de juros, e enxuga a liquidez com a venda de títulos de curto prazo e com taxas de juros mais baixas na outra ponta da curva. 
esse diferencial de taxas aumenta em períodos de elevada incerteza, como o atual, quando o aumento do prêmio de liquidez distorce a curva de juros, produzindo elevação dos juros de longo prazo em relação à taxa Selic. O primeiro ponto é ainda mais improvável, pois ninguém espera um recrudescimento da inflação diante daquela que deverá ser a maior recessão da história da economia brasileira. São esperados apenas aumentos pontuais de preços, sem grandes efeitos sobre o núcleo da inflação.

Medidas tais como a ampliação do Auxílio Emergencial, de R\$ 600,00 para um salário-mínimo e para um contingente de 100 milhões de pessoas, entre outras elencadas na Introdução deste artigo, devem ser feitas imediatamente e só são possíveis mediante emissão de moeda e de dívida pública. Dada a gravidade do quadro, a emissão monetária para financiar essas medidas já deveria estar ocorrendo desde o final de março de 2020, visto que o quadro chinês, em fevereiro, e o quadro italiano, no início de março, já deixavam claro o potencial devastador da Covid-19 para as economias. Ademais, em 11 de março de 2020 a Organização Mundial da Saúde (OMS) declarou o estado de pandemia mundial. Esse cenário não deixava dúvidas sobre o que estaria por vir, mas os economistas do governo brasileiro não entenderam a gravidade da situação.

\section{EMISSÃO DE DÍVIDA PÚBLICA E CONFIANÇA}

O combate à crise econômica deve ser feito, também, com o endividamento do governo. O dinheiro da emissão de moeda e de dívida pública precisa chegar com urgência nas mãos de governos estaduais e municipais, desempregados e empresas. Quanto maior for sua demora, maior será a recessão.

$\mathrm{O}$ aumento da relação dívida pública/PIB, quando descontrolado, incrementa a incerteza dos agentes sobre o futuro da economia. Mais importante do que o patamar da relação dívida/PIB, é a confiança do mercado na sua estabilidade. Se a dívida pública sobe descontroladamente, surge a expectativa de que futuramente o governo emitirá moeda e/ou aumentará impostos para arcar com os compromissos da sua dívida. Conforme argumentado, a monetização da dívida pública na ausência de recessão pode ser inflacionária. As dúvidas sobre o aumento de impostos (referentes à sua magnitude, aos setores produtivos e camadas da sociedade sobre os quais recairia, dentre outras) elevam a incerteza sobre o retorno dos investimentos, inibindo-os.

Todavia, a confiança na estabilidade da relação dívida/PIB já não existe mais, desfeita que foi pela pandemia, no Brasil e no mundo. Não há que se preocupar com uma confiança que já se desfez. A convenção instalada no Brasil e no mundo refere-se a aumentos substanciais das dívidas públicas dos países. Não apenas haverá severa redução na arrecadação dos governos por causa da queda da atividade econômica, como também os 
gastos públicos estão aumentando para combater a Covid-19 e a recessão. Contudo, a equipe econômica parece não entender a situação e questiona o Congresso acerca da proveniência do dinheiro, além de dar declarações preocupadas com o equilíbrio fiscal e procrastinar na implementação das medidas emergenciais, provavelmente por não querer elevar a dívida pública. De onde sairá o dinheiro? Da emissão de moeda e de dívida pública!

Uma ironia e contradição em termos surgem no âmbito dessa crise: com a incerteza elevada e o pânico permeando o mercado, é exatamente a emissão de moeda e dívida pública que poderá acalmá-lo, porque o mercado terá, assim, respostas concretas para minimizar a recessão e o desemprego, ao mesmo tempo em que aumentará sua confiança num governo (e sua política econômica) que cuida de inibir o desemprego, a recessão e uma possível convulsão social no país. Ademais, apenas a dívida pública oferece liquidez, rentabilidade e segurança. Taxas de juros de longo prazo dos títulos dos Tesouros de países avançados e emergentes em pisos históricos, mostram que o mercado não apenas aceita o aumento das dívidas públicas, como deseja esse aumento em sua busca por segurança. Ou seja, é a emissão de dinheiro novo e de dívida que poderá construir uma convenção sobre um futuro menos sombrio e uma recuperação econômica mais rápida, sendo esta crença compartilhada imprescindível para, na saída da crise, destravar o investimento privado e resgatar a economia e o emprego. A emissão de moeda pode ocorrer no Brasil por meio da suspensão do artigo 164 da Constituição Federal, para autorizar o BC a comprar emissões primárias de títulos públicos, medida que não foi contemplada na PEC do "orçamento de guerra".

\section{EFEITOS DA EMISSÃO DE MOEDA E DÍVIDA APÓS A RECESSÃO}

Finalmente, há o argumento de que, superada a recessão, o excesso de moeda e de dívida pública cobrarão sua conta, produzindo inflação e retração dos investimentos. O excesso de moeda não causará inflação futuramente. Uma característica dos ciclos econômicos é a chegada abrupta e severa da recessão, enquanto a retomada é lenta e gradual (KEYNES, 1988; MINSKY, 1986). Portanto, no início da recuperação econômica haverá muita capacidade ociosa e a elevada preferência pela liquidez irá gradualmente se reduzir, com aumento lento de V. O decorrente excesso de demanda cresce gradualmente rebatendo em aumento da oferta, pois a capacidade ociosa elevada travará o aumento dos preços e as expectativas de inflação. Nos Estados Unidos, a base monetária foi aumentada em mais de $400 \%$ após a crise de 2008 e foi esse processo que se observou passada sua recessão econômica.

No pós-crise, a relação dívida/PIB estará mais alta, mas não produzirá, necessariamente, a perda de confiança na sua estabilidade, pois essa confiança depende, também, da convenção reinante. Se todos os países terão sua relação dívida/PIB aumentada após 
a crise, uma nova crença compartilhada surgirá indicando que patamares mais elevados dessa relação são o "novo normal”. Ademais, não necessariamente a posição relativa do Brasil irá piorar no ranking internacional da relação dívida/PIB, sendo que quanto maior for nossa emissão monetária, menor poderá ser nossa emissão de dívida. Isso não quer dizer que a citada relação seja necessariamente sustentável ao longo do tempo. Todavia, há uma área cinzenta para o patamar da relação dívida/PIB a partir do qual esta se torna insustentável, e tal área é ampla. Convencionou-se, a partir de um estudo de Reinhart e Rogoff publicado em 2010 na American Economic Review, que esse patamar seria de $90 \%$, até ter sido constatado um erro básico nas contas dos autores. Ou seja, a marca (mágica) de $90 \%$ era apenas mera convenção. Segundo a Trading Economics (2020), no Japão, a dívida é de 230\% do PIB, na Itália 135\%, na Grécia 181\%, em Portugal 118\%, nos Estados Unidos 107\%, em Angola 111\%, no Congo 98,5\%, na Jordânia 94\%, no Brasil 76\% - constata-se que há nessa lista países desenvolvidos e emergentes, todos com a relação dívida/PIB bem superior à do Brasil.

A dinâmica da relação dívida/PIB depende da taxa de crescimento do PIB e da taxa de juros que incide sobre a dívida pública. Após a crise, no início da recuperação econômica, haverá muita capacidade ociosa e expectativa de baixa inflação, aqui e alhures, implicando baixas taxas de juros. Ademais, uma reforma tributária progressiva, segundo a qual ricos paguem mais impostos do que pobres, proporcionalmente a sua renda e patrimônio, pode e deve ser feita, pois sinalizaria para o mercado a capacidade do governo em honrar seus compromissos financeiros e contribuiria para estabilizar a relação dívida/PIB, bem como para reduzir a enorme e recalcitrante injustiça social que há muito assola nosso povo.

\section{CONCLUSÃO}

A recessão causada pela pandemia de Covid-19 poderá ser a maior da história da economia brasileira. Devido a suas características, de mergulho rápido e profundo da atividade econômica, o único caminho seguro para combater a recessão e o desemprego é a emissão massiva de moeda e dívida pública, a fim de transferir urgentemente recursos monetários em montantes bem superiores aos atuais para desempregados, empresas, estados e municípios, paralelamente às políticas monetária e fiscal contracíclicas tradicionais.

São imprescindíveis programas de urgente implementação, tais como: transferência de renda para cerca de 100 milhões de pessoas; crédito para MPE e médias empresas com taxa de juros zero somada à taxa de intermediação bancária, 100\% de garantia do Tesouro Nacional, carência de dois anos, vinculado ao pagamento da folha salarial e à manutenção dos empregos; isenção temporária de impostos para empresas; e transferência de recursos 
para estados e municípios. Para a implementação dessas medidas emergenciais, não devem ser poupados recursos, cuja fonte seria a emissão de moeda e de dívida pública.

Este artigo procurou demonstrar que nem sempre a emissão de moeda é inflacionária. Os elevados níveis de capacidade ociosa no setor produtivo e no mercado de trabalho, provocados pela recessão, representarão uma âncora para a inflação de demanda e para as expectativas de inflação, durante a crise da economia e durante sua recuperação. Argumentou-se, também, que a emissão monetária não levará ao aumento, na mesma proporção, da dívida pública por meio da elevação das operações compromissadas. A meta Selic pode ir sendo reduzida paralelamente à ampliação da base monetária, pois o risco de inflação é pequeno se não houver intensa depreciação cambial. Ademais, outros fatores que condicionam a variação da base monetária podem ocorrer e mitigar a necessidade das compromissadas.

Do mesmo modo, a política econômica não deve mirar, durante a recessão, na estabilidade da relação dívida/PIB para preservar algo que já não existe: a confiança do mercado na estabilidade dessa relação. A convenção predominante é de aumentos substanciais da relação dívida/PIB em todos os países. Passada a pandemia, patamares mais elevados para essa relação em todo o mundo serão o "novo normal" e a confiança do mercado poderá ser restabelecida, desde que o governo brasileiro possa sinalizar que a relação dívida/PIB será novamente estabilizada. Na medida em que a estabilização dessa relação depende de a taxa de juros ser menor do que a taxa de crescimento econômico (RESENDE, 2019), tal sinalização será viável num contexto de um mundo pós-recessão marcado por expectativas de inflação muito baixa e, consequentemente, taxas juros diminutas. De outro lado, uma reforma tributária progressiva contribuirá, juntamente com a prática de baixas taxas de juros, para estabilizar a relação dívida/PIB, além de reduzir a enorme e recalcitrante injustiça social que há muito assola nosso povo.

Ironicamente, com a incerteza e o pânico permeando o mercado, somente a implementação de medidas emergenciais a partir da emissão massiva de moeda e dívida pública poderá acalmá-lo, pois o Estado e sua política econômica estariam emitindo sinais claros de sustentação da renda agregada, inclusive afastando um possível caos social. Ademais, somente a dívida pública oferece ao mercado liquidez, rentabilidade e segurança. Apenas com essas medidas será possível resgatar a confiança dos agentes e mitigar a queda da atividade econômica já iniciada, facilitando posteriormente a retomada do crescimento econômico.

\section{REFERÊNCIAS}

ANDERSON, R. G.; BORDO, M.; DUCA, J. Money and velocity during financial crises: from the Great Depression to the Great Recession. Working Paper, Federal Reserve Bank of Dallas Research Department, n. 1503, p. 1-59, 2015. 
BARBOSA, N. Financiamento do Tesouro. Folha de S.Paulo, São Paulo, 8 mai. 2020.

CARVALHO, F. J. C. Expectativas, incerteza e convenções. In: MONTEIRO FILHA, D.; PRADO, L. C. D.; LASTRES, H. M. M. (Orgs.). Estratégias de desenvolvimento, política industrial e inovação: ensaios em memória de Fabio Erber. Rio de Janeiro: BNDES, 2014. p. 235-258.

CARVALHO, F. J. C. Keynes on expectations, uncertainty and defensive behavior. Brazilian Keynesian Review, v. 1, n. 1, p. 44-54, 2015.

CARVALHO, F. J. C. Moeda, produção e acumulação: uma perspectiva Pós Keynesiana. In: Silva, M. L. F. (Org.). Moedas e produção: Teoria comparadas. Brasília, DF: Ed. UnB, 1992a. p. 163-191.

CARVALHO, F. J. C. Mr. Keynes and the Post Keynesians. Aldershot: Edward Elgar, 1992b.

CARVALHO, F. J. C.; SICSU, J. Controvérsias recentes sobre controles de capitais. In: SICSÚ, J. Emprego, juros e câmbio: Finanças globais e desemprego. Rio de Janeiro: Elsevier, 2007. p. 115-144.

DEQUECH, D. Incerteza num sentido forte: significado e fontes. In: LIMA, G. T.; SICSÚ, J.; PAULA, L. F. (Orgs.). Macroeconomia moderna: Keynes e a economia contemporânea. Rio de Janeiro: Ed. Campus, 1999a. p. 88-108.

DEQUECH, D. On some arguments for the rationality of conventional behaviour under uncertainty: concepts, applicability and criticisms. In: SARDONI, C.; KRIESLER, P. (Eds.). Keynes, Post-Keynesianism and political economy. London: Routledge, 1999b. p. 176-195.

DOW, S. C. Post Keynesian monetary theory for an open economy. Journal of Post Keynesian Economics, v. 9, n. 2, p. 237-257, winter 1986.

FMI - FUNDO MONETÁRIO INTERNACIONAL. World economic outlook. [S.l.] IMF, 2020. Disponível em: https://www.imf.org/en/Publications/WEO/Issues/2020/09/30/worldeconomic-outlook-october-2020. Acesso em: nov. 2020.

GENTLE, P. F.; JONES, J. Reflections concerning the money supply, velocity, and the quantity theory of money: The Great Depression and the Great Recession in the United States. Banks and Bank Sytems, v. 10, n. 2, p. 72-82, 2015.

GOLDFAJN, I. Emitir moeda como solução sem custos parece voluntarismo perigoso. Folha de São Paulo, São Paulo, 4 mai. 2020.

IBGE - INSTITUTO BRASILEIRO DE GEOGRAFIA E ESTATÍSTICA. Sistema de Contas Nacionais Trimestrais. [On-line] IBGE, 2020. Disponível em: https://www.ibge.gov.br/ estatisticas/economicas/contas-nacionais/9300-contas-nacionais-trimestrais.html $=\& \mathrm{t}=$ resultados. Acesso em: nov. 2020.

KEYNES, J. M. A Teoria geral do emprego, do juro e da moeda. São Paulo: Nova Cultural, 1936 [1988].

MARCONI, N. O governo deveria emitir mais moeda para enfrentar a crise econômica? Sim. Folha de São Paulo, São Paulo, 9 mai. 2020.

MINSKY, H. P. Stabilizing and unstable economy. New Haven: Yale University Press 1986.

MODENESI, A. M.; MODENESI, R. L. Development conventions: Theory and the case of Brazil in the latter half of the twentieth century. Journal of Post Keynesian Economics, v. 38, n. 1, p. 131-161, 2015.

MODENESI, A. M.; MODENESI, R. L.; OREIRO, J. L.; MARTINS, N. M. Convention, interest rates and monetary policy: A post-Keynesian-French-conventions-school approach. European Journal of Economics and Economic Policies: Intervention, v. 10, n. 1, p. 76-92, 2013. 
MODENESI, A. M.; PIMENTEL, D. O Banco Central Ideal: Meta de emprego e financiamento ao Tesouro. Texto para Discussão do IE-UFRJ, n. 017, ago. 2020. Disponível em: https://www. ie.ufrj.br/images/IE/TDS/2020/TD_IE_017_2020_MODENESI_PIMENTEL.pdf. Acesso em: nov. de 2020.

MOLLO, M. L. R. Ortodoxia e heterodoxia monetárias: a questão da neutralidade da moeda. Revista de Economia Política, v. 24, n. 3, p. 323-345, jul./set. 2004.

MOREIRA, T. Procura por linha de crédito para folha de pagamento chega só a $35 \%$ da oferta. Valor Investe, Brasília, DF, 29 abr. 2020. Disponível em: https://valorinveste.globo.com/ produtos/credito/noticia/2020/04/29/procura-por-linha-para-folha-de-pagamento-chega-soa-35percent-da-oferta.ghtml. Acesso em: 30 abr. 2020.

OREIRO, J. L. C. A forma pela qual o governo financia seu déficit afeta a inflação? Blog do Oreiro, 3 mai. 2020. Disponível em: https://jlcoreiro.wordpress.com/2020/05/03/a-forma-pelaqual-o-governo-financia-o-seu-deficit-afeta-a-inflacao/. Acesso em: 03/05/2020.

PAULA, L. F.; FERREIRA, M. C. A crise do coronavírus e a atuação do Banco Central. Blog A Terceira Margem, [S. l.], 2020. Disponível em: https://aterceiramargem.org/2020/05/ 13/a-crise-do-coronavirus-e-a-atuacao-do-banco-central/. Acesso em: 13 maio 2020.

PAULA, L. F.; OREIRO, J. L.; SILVA, G. Fluxos e controle de capitais no Brasil: avaliação e proposta de política. In: SICSÚ, J.; OREIRO, J. L.; PAULA, L. F. (Orgs.). Agenda Brasil: Políticas econômicas para o crescimento com estabilidade de preços. São Paulo: Manole, 2003. p. 65-116.

PESSÔA, S. Imprimir dinheiro contra a crise? Folha de São Paulo, São Paulo, 3 mai. 2020.

RESENDE, A. L. Consenso e contrassenso: Déficit, dívida e previdência. Portal Finance, [S. l.], 2019. Disponível em: https://www.joserobertoafonso.com.br/consenso-e-constrassensoresende/. Acesso em: 30 maio 2020.

RESENDE, M. F. C. Taxa de câmbio na perspectiva pós-Keynesiana. In: FEIJÓ, C.; ARAÚJO, E. Macroeconomia Moderna: Lições de Keynes para economias em desenvolvimento. Rio de Janeiro: Elsevier, 2019. p. 113-125.

RESENDE, M. F. C; TERRA, F. B. Economic and social policies inconsistency, conventions and crisis in the Brazilian economy: 2011-2016. In: ARESTIS, P.; BALTAR, C. T.; PRATES, D. M. (Eds.). The Brazilian economy since the great financial crisis of 2007/2008. Londres: Palgrave Macmillan, 2017. p. 245-272.

REUTERS. Banco Central vai imprimir dinheiro para pagar auxílio emergencial. Money times, [S. l.], 2020. Disponível em: www.moneytimes.com.br/banco-central-vai-imprimir-dinheiropara-pagar-auxilio-emergencial/. Acesso em: 8 maio 2020.

RITTNER, D. América Latina ruma para juro real negativo. Valor Investe, Brasília, DF, 11 mai. 2020b. Disponível em: https:/valorinveste.globo.com/noticia/2020/05/11/america-latinaruma-para-juro-real-negativo.ghtml. Acesso em: 11 maio 2020.

TERRA, F. H. B. A política fiscal na perspectiva Pós-Keynesiana. In: FEIJÓ, C.; ARAÚJO, E. Macroeconomia Moderna: Lições de Keynes para economias em desenvolvimento. Rio de Janeiro: Elsevier, 2019. p. 57-67.

TRADING ECONOMICS. Dívida Pública \% Pib - Lista de Países. [On-line] Trading Economics, 2020. Disponível em: https://pt.tradingeconomics.com/country-list/government-debt-to-gdp. Acesso em: 30 abr. 2020. 
TYMOIGNE, E.; WRAY, L. R. Modern Money Theory 101: A replay to critics. Working Paper, Levy Economics Institute of Bard College, n. 778, nov. 2013.

WRAY, L. R. Understanding modern money: The key to full employment and price stability. Aldershot: Edward Elgar, 1998.

ZILBERMAN, E.; SILVA, D. O governo deveria emitir mais moeda para enfrentar a crise econômica? Não. Folha de S. Paulo, São Paulo, 9 mai. 2020. 